\title{
Alt ve Üst Ekstremite Damar Yaralanmaları: On İki Yıllık Deneyimimiz
}

\author{
Atıf YOLGÖSTEREN, Mustafa YALÇIN, İrem İris KAN, Mustafa TOK, \\ Işık ŞENKAYA SIĞNAK, Murat BİÇER
}

Bursa Uludağ Üniversitesi Tıp Fakültesi, Kalp ve Damar Cerrahisi Anabilim Dalı, Bursa.

\section{ÖZET}

Ekstremite damar yaralanması nedeniyle merkezimize başvuran hastaları değerlendirme protokollerimizi, tedavi yöntemlerimizi ve sonuçlarımızı literatür eşliğinde retrospektif olarak değerlendirmeyi amaçladık. Ocak 2007-Aralık 2019 tarihleri arasında Uludağ Üniversitesi Tıp Fakültesi Kalp ve Damar Cerrahisi Kliniğinde periferik damar yaralanması nedeniyle ameliyat edilen hastaların yaş ve cinsiyet bilgileri, yaralanma ile ameliyata alınma arasında geçen süre, preoperatif değerlendirme bilgileri, yaralanan damar segmentleri, yaralanma mekanizmaları, damar onarım teknikleri, postoperatif erken dönem ve 30. günde ki kontrol bilgileri retrospektif olarak incelendi. Çalışmaya 102 hasta dahil edildi (\%9.8'i kadın, \%90.2'si erkek; yaş ortalaması 28.9). Hastaların 28'si ateşli silah yaralanması (\%27.4), 37'si delici-kesici alet yaralanması (\%36.3), 37’si künt yaralanmaydı (\%36.3). Hastaların iskemi süreleri 1-8 saati. Seksen dört hastaya otojen greft ile (vena safena magna) baypas (\%82.4), 7 hastaya PTFE sentetik ringli damar grefti ile baypas (\%6.8), 10 hastaya uç-uca anastomoz, 1 hastaya da safen ven greftiyle patch-plast yapıldı (\%1). Yirmi iki hastaya fasyatomi açıldı (\%21.5). Beş hastaya amputasyon uygulandı (\%4.9). İki hasta ex oldu (\%1.9). Ekstremite damar yaralanmalı hastaları değerlendirme ve tedavi protokollerimiz ile cerrahi sonuçlarımız literatürdekilerle benzerlik göstermektedir Periferik damar yaralanmalarında mortalite ve morbidite oranlarını azaltmak için multidisipliner yaklaşımın, hızlı tanı ve tedavinin en önemli faktörler olduğunu düşünüyoruz. Ayrıca preoperatif görüntüleme gereken hastalarda ilk tercihin BT anjiografi olması gerektiğini, damar onarımında mümkün olan tüm hastalarda otojen greft kullanılmasının en doğru yaklaşım olduğunu ve uzun süreli iskemilerde ampütasyon oranlarını düşürmek için fasyatomi yapılması gerektiğini düşünüyoruz.

Anahtar Kelimeler: Damar yaralanması. Amputasyon. Fasyatomi.

Lower and Upper Extremity Vascular Injuries: Our 12-Year Experience

\begin{abstract}
We aimed to retrospectively evaluate our evaluation protocols, treatment methods and results of patients admitted to our center with limb vascular injury in the light of the literature. Age and gender information of patients who were operated for peripheral vascular injury between January 2007 and December 2019 in Uludağ University Faculty of Medicine Cardiovascular Surgery Clinic, time between injury and operation, preoperative evaluation information, injured vessel segments, injury mechanisms, vessel repair techniques, early postoperative period, and control data on the 30th day were retrospectively analyzed. 102 patients were included in the study ( $9.8 \%$ female, $90.2 \%$ male; mean age 28.9). Twenty-eight of the patients were gunshot wounds injury (27.4\%), 37 were sharp object injurie (36.3\%), 37 were blunt injuries (36.3\%). The ischemia times of the patients were 1-8 hours. Eighty-four patients underwent bypass with autogenous graft (vena saphena magna) (82.4\%), 7 patients with PTFE synthetic ringed vein graft (6.8\%), 10 patients underwent end-to-end anastomosis, 1 patient was performed patch-plasty with saphenous vein graft (\%). one). Fasciotomy was performed in 22 patients (21.5\%). Amputation was performed in five patients (4.9\%). Two patients died (1.9\%). Our evaluation and treatment protocols for patients with extremity vascular injury and our surgical results are similar to those in the literature. We think that multidisciplinary approach, rapid diagnosis and treatment are the most important factors in reducing mortality and morbidity rates in peripheral vascular injuries. In addition, we think that CT angiography should be the first choice in patients who require preoperative imaging, that the use of autogenous grafts is the most appropriate approach in all possible patients in vascular repair, and fasciotomy should be performed to reduce amputation rates in long-term ischemia.
\end{abstract}

Key Words: Vascular injury. Amputation. Fasciotomy.

Geliş Tarihi: 23.Ekim.2020

Kabul Tarihi:09.Kasım.2020

Dr. Atıf YOLGÖSTEREN

Bursa Uludağ Üniversitesi Tıp Fakültesi,

Kalp ve Damar Cerrahisi Anabilim Dalı,

Bursa.

Tel: 05053103333

E-posta: atif@uludag.edu.tr
Yazarların ORCID ID Bilgisi:

Atıf YOLGÖSTEREN: 0000-0002-4467-3915

Mustafa YALÇIN: 0000-0003-0134-3163

İrem İris KAN: 0000-0002-1600-9531

Mustafa TOK: 0000-0001-9656-537X

Işık ŞENKAYA SIĞNAK: 0000-0001-8813-4481

Murat BiÇER: 0000-0002-9011-2609 


\section{A. Yolgösteren, ark.}

Damar yaralanmaları travma hastalarında mortalite ve morbiditeyi arttıran en önemli etkendir ${ }^{1}$. Ekstremitelerde daha sık görülmektedir ve erkeklerde görülme oranı kadınlara göre daha yüksektir. Ekstremite damar yaralanmalarının \%50-60'nın femoral veya popliteal arterde, \%30'nun brakial arterde ve \%10-20'sinin diğer damarlarda görüldüğü belirtilmektedir ${ }^{2}$. Oluş mekanizmalarına göre bu yaralanmalar penetran (ateşli silah ile veya delici-kesici alet ile) veya künt mekanizmalarla olmaktadır. Penetran yaralanmalar daha s1k görülmektedir ve daha iyi prognoza sahiptir. Künt yaralanmalar daha az görülmekle birlikte yüksek mortalite ve amputasyon oranları ile ilişkilidir ${ }^{3}$.

Ekstremite damar yaralanmalarında iyi prognoz için en önemli faktör yaralanma anından tedavi başlayana kadarki zamanda hızlı ve doğru kararlarla sürecin yönetilmesidir. Geçmiște ekstremite damar yaralanmalarında ekstremite kaybı \%30-70 iken günümüzde resüsitasyon protokollerinde, tanı koyma tekniklerinde, cerrahi tekniklerde ve postoperatif yönetimdeki gelişmeler sayesinde bu oranlar penetran yaralanmalarda \%0.5-4'e, künt yaralanmalarda \%6-20’ye kadar düşmüştür ${ }^{4}$. Tüm bunlara rağmen ekstremite travmalarında prognozu belirleyen en önemli etken hala damar yaralanmalarıdır.

Biz çalışmamızda damar yaralanması nedeniyle merkezimize başvuran hastaları değerlendirme protokollerimizi, tedavi yöntemlerimizi ve sonuçlarımızı literatür eşliğinde retrospektif olarak değerlendirmeyi amaçladık

\section{Gereç ve Yöntem}

Ocak 2007-Aralık 2019 tarihleri arasında Uludağ Üniversitesi Tıp Fakültesi Kalp ve Damar Cerrahisi Kliniğinde periferik (alt ve üst ekstremite) damar yaralanması nedeniyle ameliyat edilen hastalar retrospektif olarak incelendi. Çalışma için Uludağ Üniversitesi Tıp Fakültesi Klinik Araştırmalar Etik Kurulu'ndan onay alındı (tarih: 12 Şubat 2019; karar no: 2019-3/21). Hastaların yaş ve cinsiyet bilgileri, yaralanma ile ameliyata alınma arasında geçen süre, preoperatif değerlendirme bilgileri, yaralanan damar segmentleri, postoperatif erken dönemde ve 30 . günde ki kontrol bilgileri incelendi. Yaralanma mekanizması, damarın yaralanma şekli ve damar onarım teknikleri sinıflandirıldı:

1. Yaralanma mekanizması: Ateşli silah, delici-kesici ve künt

2. Damarın yaralanma şekli: Transeksiyon, laserasyon ve intimal hasar

3. Damar onarım tekniği: Otojen ven grefti, polytetrafluoroethylene (PTFE) sentetik damar grefti, uçuca anastomoz ve patch-plasti
Operasyon sırasında kaybedilen hastalar ile 30. gün kontrol bilgileri olmayan hastalar çalışmaya alınmadı.

\section{Bulgular}

Çalışmaya 102 hasta dahil edildi. Hastaların 10'u kadın (\%9.8), 92'si erkekti (\%90.2) ve yaş ortalaması 28.9 idi (1-74 yaş). Hastaların büyük çoğunluğu 18-40 yaş erkekti. Yaralanma ile ameliyata alınma arasında geçen süre 1-8 saatti.

Hastaların 28'si ateşli silah yaralanması (\%27.4), 37'si delici-kesici alet yaralanması (\%36.3), 37’si künt yaralanmaydı (\%36.3). Hastaların 56'sinda (\%55) alt ekstremite yaralanması, 46'sında (\%45) üst ekstremite yaralanması vardı. Yirmi sekiz hastada (\%27.5) eş zamanlı ven yaralanması vardı. Alt ve üst ekstremitede yaralanan derin venler ameliyattaki bulgularla değerlendirilerek yaralanma şekline göre uygun teknikle onarıld1. Üst ekstremite ve alt ekstremitede yaralanan yüzeyel venler bağlandı. Yaralanan damar lokalizasyonları Tablo I’de gösterilmiştir.

Tablo I. Yaralanan damar lokalizasyonları

\begin{tabular}{|lcccccc}
\hline Yaralanan Damar & \multicolumn{2}{c}{ Arter } & \multicolumn{2}{c}{ Arter+Ven } & \multicolumn{2}{c}{ Total } \\
& $n$ & $\%$ & $n$ & $\%$ & $n$ & $\%$ \\
Alt ekstremite & 38 & 37,3 & 18 & 17,6 & 56 & 55 \\
CFA & 2 & 2,0 & 1 & 1,0 & 3 & 2,9 \\
PFA & 0 & 0,0 & 1 & 1,0 & 1 & 1 \\
SFA & 12 & 11,8 & 11 & 10,8 & 23 & 22,5 \\
PA & 14 & 13,7 & 5 & 4,9 & 19 & 18,6 \\
ATA velveya ATP & 4 & 3,9 & 0 & 0,0 & 4 & 3,9 \\
SFA ve ATA & 1 & 1,0 & 0 & 0,0 & 1 & 1 \\
CFA+ATA & 2 & 2,0 & 0 & 0,0 & 2 & 2 \\
CFA+PFA & 2 & 2,0 & 0 & 0,0 & 2 & 2 \\
CFA+PA & 1 & 1,0 & 0 & 0,0 & 1 & 2 \\
Üst ekstremite & 36 & 35,3 & 10 & 9,8 & 46 & 45 \\
Aksiller arter & 3 & 2,9 & 4 & 3,9 & 7 & 6,9 \\
Brakiyal arter & 32 & 31,4 & 5 & 4,9 & 37 & 36,3 \\
Brakiyal ve radyal arter & 1 & 1,0 & 1 & 1,0 & 2 & 2 \\
Toplam & 74 & & 28 & & 102 & \\
\hline
\end{tabular}

CFA: Common femoral arter; PFA: Profunda femoral arter; SFA: Süperfisiyal femoral arter; PA: Popliteal arter; ATA: Arteria tibialis anterior; ATP: Arteria tibialis posterior

Güçlü bulgulara sahip (distal nabız yokluğu, ilerleyen veya pulsatil hematom, üfürüm veya trill, aktif kanama, distal kritik iskemi bulguları) tüm hastalar ek tetkik yapılmadan acil ameliyata alındı. Hemodinamisi bozuk ve hemoglobini düşük hastalarda turnike veya kompresyonla kanama kontrol altına alınıp hemodinamisinin düzelmesi ve hemoglobinin yükselmesi sağlandıktan sonra yaralanma bölgesi eksplore edildi. Zayıf bulgulara sahip (kontralateral ekstremiteye göre azalmış nabız, büyük non-pulsatil hematom, nörolojik defisit, olay yerinde büyük kanama, yüksek riskli ortopedik travma) hastalara fizik muayeneneye ek 


\section{Periferik Damar Yaralanmaları}

olarak bilgisayarlı tomografik (BT) anjiografi yapıldı. Kontrast alması kontrendike olan az sayıda hastaya doppler ultrasonografi (USG) yapıldı. BT anjiografi veya doppler USG ile tanı konulduktan sonra hastalar ameliyata alındı. Tüm hastalara preoperatif ve postoperatif antibiyotik profilaksisi yapıldı.

Damar onarımı öncesi tüm hastalara 100 Ü/kg intravenöz standart heparin yapıldı. Tüm hastalarda Fogarty katater ile damarın proksimaline ve distaline trombektomi yapıldı. Damarın yaralanma şekline ve operasyon bulgularına göre onarım tekniğine karar verildi. Buna göre; 84 hastaya otojen greft ile (vena safena magna) baypas/interpozisyon (\%82.4), 7 hastaya PTFE sentetik ringli damar grefti ile baypas/interpozisyon (\%6.8), 10 hastaya uç-uca anastomoz (\%9.8), 1 hastaya da safen ven greftiyle patchplasti yapıldı (\%1). Tüm hastalara postoperatif erken dönemde oral asetil salisilik asit ile subkutan düşük molekül ağırlıklı heparin, uzun dönemde ise oral asetil salisilik asit verildi. Yaralanma mekanizması ve damarın yaralanma şekline göre damar onarım teknikleri Tablo II'de gösterilmiştir.

Tablo II. Yaralanma şekli ve yaralanma mekanizmasına göre damar onarım teknikleri

\begin{tabular}{|c|c|c|c|c|c|c|c|c|c|}
\hline & & & $\begin{array}{l}\text { ojen } \\
\text { ft ile } \\
\text { pass }\end{array}$ & & $\begin{array}{l}\text { FE } \\
\text { tetik } \\
\text { ft ile } \\
\text { lass }\end{array}$ & & $\begin{array}{l}\text {-uca } \\
\text { las- } \\
\text { moz }\end{array}$ & & $\begin{array}{l}\text { tch } \\
\text { sty }\end{array}$ \\
\hline & & $n$ & $\%$ & $\mathrm{n}$ & $\%$ & $\mathrm{n}$ & $\%$ & $\mathrm{n}$ & $\%$ \\
\hline Yaralanma & Transeksiyon & 62 & 60,8 & 3 & 2,9 & 5 & 4,9 & 0 & 0,0 \\
\hline & Laserasyon & 15 & 14,7 & 4 & 3,9 & 5 & 4,9 & 1 & 1,0 \\
\hline & İntimal hasar & 7 & 6,9 & 0 & 0,0 & 0 & 0,0 & 0 & 0,0 \\
\hline & Toplam & 84 & 82,4 & 7 & 6,8 & 10 & 9,8 & 1 & 1,0 \\
\hline Yaralanma & Ateşli silah & 25 & 24,5 & 3 & 2,9 & 0 & 0,0 & 0 & 0,0 \\
\hline mekanız- & Delici-Kesici & 24 & 23,5 & 2 & 2,0 & 10 & 9,8 & 1 & 1,0 \\
\hline & Künt & 35 & 34,3 & 2 & 2,0 & 0 & 0,0 & 0 & 0,0 \\
\hline & Toplam & 84 & 82,4 & 7 & 6,8 & 10 & 9,8 & 1 & 1,0 \\
\hline
\end{tabular}

PTFE: Polytetrafluoroethylene

Ateşli silahla yaralanan 5 hastaya (\%4.9), delicikecisici aletle yaralanan 4 hastaya (\%3.9) ve künt yaralanması olan 13 hastaya (\%12.7) kompartman sendromu nedeniyle fasyatomi açıldı (toplam 22 hasta, \%21.5). Otuz bir hastaya (\%30.3) sinir yaralanmas1 nedeniyle sinir onarımı yapıldı. Yaygın kas nekrozu ve enfeksiyon nedeniyle künt travması olan 3 hastada diz altı bacak, 2 hastada kol amputasyonu yapıldı (\%4.9). Postoperatif takipte 1 hasta enfeksiyona bağl1 sepsis nedeniyle, 1 hasta da akut böbrek yetmezliği nedeniyle ex oldu (\%1.9).

Alt ekstremite yaralanması olan hastaların postoperatif 30.günde yapılan kontrollerinde ateşli silahla yaralanan 2 hastada, delici-kesici aletle yaralanan 1 hastada ve künt yaralanması olan 2 hastada 700-1000 metrede başlayan kladikasyo şikayeti vardı (\%4.9). Bu hastala- ra yapılan dijital subtraksiyon anjiografide (DSA) kollateraller yoluyla bacak distal akımı iyi olduğu ve iskemi bulguları olmadığı için medikal tedavi ile takip edilmesine karar verildi. Üst ekstremite yaralanması olan hastaların 30.gündeki kontrollerinde vasküler açıdan sorun görülmedi.

\section{Tartışma ve Sonuç}

Damar yaralanmaları tüm travma hastalarının \%13'ünde görülmesine rağmen bu hastaların kötü prognozundan sorumlu en önemli etkendir. Ayrıca tüm damar yaralanmalarının \%30-70'inden ekstremite damarları sorumludur ${ }^{1,5}$. Bu bölgelerdeki yaralanmalar ekstremite dışındaki damar yaralanmalarına kıyasla daha düşük mortalite oranlarına sahipken yüksek morbidite ile ilişkilidirler ${ }^{6}$. Ekstremite damar yaralanmalar1 genç erkeklerde daha sık görülmektedir ${ }^{2,7}$. Bizim hastalarımızın çoğunluğunu da genç erkekler oluşturmaktayd1.

$\mathrm{Bu}$ tür yaralanmalarda ilk hedef hastanın hayatını kurtarmak, ikinci hedef ise ekstremiteyi kurtarmaktır. Hastayla ilk karşılaşan sağlık ekibinin ilk müdahalesinden damar onarımı sonrası takip sürecine kadarki tüm evreler bağımsız olarak bu hastaların prognozunu belirlemektedir. Kompresyon veya turnikeyle kanamayı engelleyip hemodinamiyi düzeltmeye yönelik girişimler sonrası hızlı bir şekilde tedavi aşamasına geçilmesi ekstremitenin kurtarılması için hayati öneme sahiptir. Turnike kullanımı bazı araştırmacılar tarafından tartışılmasına rağmen yakın zamanda yapılan birçok çalışma turnike kullanımını destekleyen sonuçlar göstermektedir. Inaba K. ve arkadaşları yaptıkları bir çalışmada, hemodinamiyi bozan ekstremite kanamalarında damar onarımına kadar geçen sürede 2 saate kadar turnike kullanımının ekstremite kaybına yol açmadığını belirtmişlerdir ${ }^{7}$. Savaş sırasında ekstremite damar yaralanması olan 455 askerle yapılan bir savaş cerrahisi çalışmasında turnike kullanımının ampütasyon ve mortaliteyi etkilemediği, kabul edilebilir oranda sinir hasarına yol açtığ 1 bildirilmiştir ${ }^{8}$. Biz acil serviste gördüğümüz aktif kanamalı tüm hastalarda cerrahi eksplorasyona kadar geçen sürede kompresyon veya turnikeyle kanamayı kontrol altına aldık. Eksplorasyon sırasında kontrol edilmesi zaman alacak bir kanama olması ihtimaline karşı replasman tedavisi ile hemodinami ve hemoglobin seviyesi optimum düzeye geldikten sonra ameliyata başladık.

Araştırmacıların birçoğu periferik damar yaralanmalarında hızlı ve doğru karar verebilmek için hastaları 'güçlü bulgulara sahip' ve 'zayıf bulgulara sahip' şeklinde muayene bulgularına göre sınıflandırmaktadırlar. Buna göre güçlü bulguları olan hastaların acil ameliyata alınması gerektiği, zayıf bulgulara sahip hastalarda ise gerektiğinde ek tetkiklerle damar yaralanmasının doğrulanması gerektiği önerilmekte- 


\section{A. Yolgösteren, ark.}

dir ${ }^{1,10,11}$. Biz ekstremite damar yaralanması olan tüm hastalarımızı bu protokole göre değerlendirerek tedavimizi belirledik. Bununla birlikte travma hastalarının yalnızca \%10'nun güçlü bulgulara sahip olması ve damar yaralanmalı bazı hastaların asemptomatik olması nedeniyle tüm travma hastalarının damar yaralanması açısından değerlendirilmesi gerektiğini düşünüyoruz $^{12}$.

Ekstremite damar yaralanmalarının \%60-70’i penetran (ateşli silah veya delici-kesici alet ile) mekanizmalarla meydana gelmektedir ${ }^{1,2,13}$. Bizim hastalarımızın da yaklaşık \%65'inde penetran yaralanma mevcuttu. Penetran yaralanmalarda klinik bulgular tanı koymak için genellikle yeterli olmaktadır. Künt damar yaralanmaları ise nadir görülmekle birlikte daha kötü prognozla seyretmektedir. Künt travmaların genellikle multitravmayla birlikte olması, tanı konulmada gecikme olması, eşlik eden sinir yaralanması ve uzun damar segmentini etkilemesi kötü prognozun sebepleri arasında sayılabilir ${ }^{10,14}$. Bu nedenle özellikle klinik bulgu vermeyen künt travma hastalarında görüntüleme yöntemleri önem kazanmaktadır. Literatürdeki bazı çalışmalarda zayıf bulguları olan hastalarda anklebrakial indeks'in (ABİ) $\geq 0.9$ olmasının damar yaralanmasını ekarte etmek için yeterli olduğu belirtilmektedir $^{15,16}$. Fakat olası bir periferik arter hastalığı veya medial kalsinozis gibi durumlarda ABİ'in güvenilirliği azalmaktadır. $\mathrm{Bu}$ nedenle biz klinik bulgularla tanı koyamadığımız hastalarda ilk olarak BT anjiografiyi tercih ettik. Son yıllarda bu konuyla ilgili çalışmalar da bu tür hastalarda BT anjiografinin standart kullanıma girdiğini rapor etmektedir ${ }^{17,18}$.

Literatürde ki çalışmalar damar çevresinin \%25’inden fazlasında yaralanma olduğunda (laserasyon varlığında bile) distal emboli riskinin yüksek olduğunu, bu nedenle bu durumlarda onarım öncesinde mutlaka embolektomi/tombektomi yapılması gerektiğini göstermektedir ${ }^{19,20}$. Biz hastalarımızın hepsinde Fogarty katater ile yaralanan damarın proksimal ve distaline trombektomi yaptıktan sonra damar onarımını yaptık. Periferik damar yaralanmalarında onarım tekniği ameliyat sırasındaki bulgulara göre karar verilmesi gereken bir konudur. Bazı araştırmacılar $2 \mathrm{~cm}$ 'den küçük defektlerde uç-uca anastomozu önerirlerken, bazıları ise $2 \mathrm{~cm}$ 'den küçük defektlerde bile uç-uca anastomozun damarda gerginliğe yol açabileceğini, otojen greftle baypas/interpozisyon yapılması gerektiğini savunmaktadırlar ${ }^{21}$. Uç-uca anastomoz yapılamayacak yaralanmalarda otojen greft (sıklıkla vena safena magna) ile baypas/interpozisyon birçok cerrah tarafindan kabul görmüş standart bir yaklaşımdır. Otojen greftlerin açık kalma sürelerinin uzun olması ve enfeksiyona dirençli olması bu yaklaşımın temel sebepleridir ${ }^{16,19,21}$. Kullanıma uygun otojen greft bulunamadiğında, safen ven grefti ile ilgili çap uyumsuzluğu olduğunda veya ameliyat süresinin uzatılmaması gereken hastalarda PTFE sentetik ringli greftler 2. en sik tercih edilen greftlerdir. Özellikle esnek yapılı PTFE greftlerin enfeksiyona dirençlerinin iyi olduğunu gösteren çalışmalar mevcuttur ${ }^{22}$. Biz hastalarımızın \%82.4'ünde damar onarımını safen ven greft baypas/interpozisyon ile yaptık. Damar onarım tekniklerinde ki oranlarımız literatürdeki oranlarla benzerdir.

Damar onarımının geciktiği hastalarda onarım sonrası reperfüzyon hasarına bağlı kompartman sendromu s1k karşılaşılan bir tablodur. $\mathrm{Bu}$ hastalarda fasyatomi açılması ekstremitenin kurtarılması için en önemli müdahaledir. Hatta bazı araştırmacılar 6 saatten uzun iskemi süresinde profilaktik olarak fasyatomi açılmasinı önermektedirler ${ }^{11,23}$. Fasyatominin gerektiği hastalar genellikle künt yaralanması olan ve damar onar1mının geciktiği hastalardır. Biz 22 hastamıza (\%21.5) fasyatomi açtık. Bunların 13 tanesi künt yaralanması olan hastalardı. Altı hastamıza iskemi süresi 6-8 saat olduğu için profilaktik olarak fasyatomi açtık.

Ekstremite damar yaralanmalarının en korkulan sonuçlarından birisi ekstremite kaybıdır. Tedavinin gecikmesi, künt travma, popliteal arter yaralanması ve eşlik eden ven ve sinir yaralanması amputasyon riskini arttıran faktörlerdir ${ }^{23,24}$. Jason D. ve arkadaşları, yaptıkları bir çalışmada künt popliteal arter yaralanmasının ve PTFE greft kullanımının amputasyon riskini anlamlı şekilde arttırdı ğını belirtmektedirler ${ }^{25}$. Postoperatif dönemde yaygın kas nekrozu ve şiddetli enfeksiyon gelişen 5 hastamıza amputasyon yapılmak zorunda kalındı. Bunlardan 3'ü künt popliteal yaralanması olan, 2'si künt aksiller-brakial arter yaralanması olan hastalardi.

Sonuç olarak, alt ve üst ekstremite damar yaralanması olan hastaları değerlendirme ve tedavi protokollerimiz ile sonuçlarımız literatürdekilerle benzerlik göstermektedir. Bu tür hastalarda mortalite ve morbidite oranlarını azaltmak için multidisipliner yaklaşımın, hızlı tanı ve tedavinin en önemli faktörler olduğunu düşünüyoruz. Ayrıca preoperatif görüntüleme gereken hastalarda ilk tercihin BT anjiografi olması gerektiğini, damar onarımında mümkün olan tüm hastalarda otojen greft kullanılmasının en doğru yaklaşım olduğunu ve uzun süreli iskemilerde amputasyon oranlarını düşürmek için fasyatomi yapılması gerektiğini düşünüyoruz.

Etik Kurul Onay Bilgisi:

Onaylayan Kurul: Uludağ Üniversitesi Tıp Fakültesi

Klinik Araştırmalar Etik Kurulu.

Onay Tarihi: 12.02 .2019

Karar No: $2019-3 / 21$

\section{Kaynaklar}

1. Feliciano DV, Moore FA, Moore EE, et al. Evaluation and management of peripheral vascular injury. Part 1. Western trauma association/critical decisions in trauma. J Trauma - Inj Infect Crit Care. 2011;70(6):1551-6. 


\section{Periferik Damar Yaralanmaları}

2. Frykberg ER, Schinco MA. Peripheral vascular injury. In: Feliciano DV, Mattox KL, Moore EE, eds. Trauma. 6th ed. New York, NY: McGraw- Hill; 2008:941-971.

3. Baker AC, Clouse WD. Upper extremity and junc- tional zone injuries. Rich's Vascular Trauma. 2016. p. 149-167

4. Mullenix PS, Steele SR, Andersen CA, et al. Limb salvage and outcomes among patients with traumatic popliteal vascular injury: an analysis of the National Trauma Data Bank. J Vasc Surg 2006;44(1):94-100.

5. Dorlac WC, DeBakey ME, Holcomb JB, et al. Mortality from isolated civilian penetrating extremity injury. J Trauma 2005;59(1):217-22.

6. Tan TW, Joglar FL, Hamburg NM, et al. Limb outcome and mortality in lower and upper extremity arterial injury: a comparison using the National Trauma Data Bank. Vasc Endovascular Surg 2011;45(7):592-7.

7. DuBose JJ, Savage SA, Fabian TC, et al. AAST PROOVIT Study Group. The American Association for the Surgery of Trauma PROspective Observational Vascular Injury Treatment (PROOVIT) registry: multicenter data on modern vascular injury diagnosis, management, and outcomes. J Trauma Acute Care Surg. 2015 Feb;78(2):215-22

8. Inaba K, Siboni S, Resnick S, et al. Tourniquet use for civilian extremity trauma. J Trauma Acute Care Surg. 2015;79(2):2327.

9. Kauvar DS, Miller D, Walters TJ. Tourniquet use is not associated with limb loss following military lower extremity arterial trauma. J Trauma Acute Care Surg. 2018;85(3):495-9.

10. Callcut RA, Mell MW. Modern advances in vascular trauma. Surg Clin North Am. 2013;93(4):941-61.

11. Asensio JA, Kuncir EJ, Garcia-Nunez LM, et al. Femoral vessel injuries: analysis of factors predictive of outcomes. J Am Coll Surg 2006;203(4):512-20.

12. Sekharan J, Dennis JW, Veldenz HC, et al. Continued experience with physical examination alone for evaluation and management of penetrating zone 2 neck injuries: Results of 145 cases. J Vasc Surg. 2000;32(3):483-9.
13. Slama R, Villaume F. Penetrating Vascular Injury: Diagnosis and Management Updates. Emerg Med Clin North Am. 2017 Nov;35(4):789-801

14. Baker WE, Wassermann J. Unsuspected vascular trauma: blunt arterial injuries. Emerg Med Clin North Am. 2004 Nov;22(4):1081-98.

15. Sadjadi J, Cureton EL, Dozier KC, Kwan RO, Victorino GP. Expedited treatment of lower extremity gunshot wounds. J Am Coll Surg. 2009; 209:740-745

16. Harkin DW, Dunlop DM. Vascular trauma. Surg (United Kingdom) [Internet]. 2018;36(6):306-13

17. Colip CG, Gorantla V, LeBedis CA, et al. Extremity CTA for penetrating trauma: 10-year experience using a 64-detector row CT scanner. Emerg Radiol 2017; 223: 24

18. Patterson BO, Holt PJ, Cleanthis M, et al. London Vascular Injuries Working Group. Imaging vascular trauma. Br J Surg. 2012 Apr;99(4):494-505

19. Ivatury RR, Anand R, Ordonez C. Penetrating extremity trauma. World J Surg 2015;39(6):1389-96.

20. Feliciano DV, Moore EE, West MA, et al. Western Trauma Association critical decisions in trauma: evaluation and management of peripheral vascular injury, part II. J Trauma Acute Care Surg. 2013 Sep;75(3):391-7.

21. Teixeira PGR, DuBose J. Surgical Management of Vascular Trauma. Surg Clin North Am. 2017 Oct;97(5):1133-1155.

22. Back MR. Local complications: graft infections. In: Cronenwett J, Johnston KW, editors. Rutherford's vascular surgery. 8th edition. Atlanta (GA): Elsevier Press; 2014. p. 654-72.

23. Callcut RA, Acher CW, Hoch J, et al. Impact of intraoperative arteriography on limb salvage for traumatic popliteal artery injury. J Trauma 2009;67(2):252-7

24. Scalea TM, DuBose J, Moore EE et al (2012) Western Trauma Association critical decisions in trauma: management of the mangled extremity. J Trauma Acute Care Surg 72(1):86-93

25. Sciarretta JD, Macedo FIB, Otero CA, et al. Management of traumatic popliteal vascular injuries in a level I trauma center: A 6-year experience. Int J Surg. 2015;18:136-41 
